\title{
Diversity of United States medical students by region compared to US census data
}

This article was published in the following Dove Press journal:

Advances in Medical Education and Practice

15 May 2015

Number of times this article has been viewed

\author{
Mark M Smith' \\ Steven H Rose' \\ Darrell R Schroeder ${ }^{2}$ \\ Timothy R Long' \\ 'Department of Anesthesiology, \\ Mayo Clinic College of Medicine, \\ Rochester, MN, USA; ${ }^{2}$ Division of \\ Biomedical Statistics and Informatics, \\ Mayo Clinic College of Medicine, \\ Rochester, MN, USA
}

Purpose: Increasing the diversity of the United States (US) physician workforce to better represent the general population has received considerable attention. The purpose of this study was to compare medical student race data to that of the US general population. We hypothesized that race demographics of medical school matriculants would reflect that of the general population.

Patients and methods: Published race data from the United States Census Bureau (USCB) 2010 census and the 2011 Association of American Medical Colleges (AAMC) allopathic medical school application and enrollment by race and ethnicity survey were analyzed and compared. Race data of enrolled medical students was compared to race data of the general population within geographic regions and subregions. Additionally, race data of medical school applicants and matriculants were compared to race data of the overall general population.

Results: Race distribution within US medical schools was significantly different than race distribution for the overall, regional, and subregional populations of the US $(P<0.001)$ Additionally, the overall race distribution of medical school applicants differed significantly to the race distribution of the general population $(P<0.001)$.

Conclusion: This study demonstrated that race demographics of US medical school applicants and matriculants are significantly different from that of the general population, and may be resultant of societal quandaries present early in formal education. Initiatives targeting underrepresented minorities at an early stage to enhance health care career interest and provide academic support and mentorship will be required to address the racial disparity that exists in US medical schools and ultimately the physician workforce.

Keywords: United States, medical school application, medical school admission, race distribution, population demographics

\section{Introduction}

Increasing the diversity of the United States (US) physician workforce to better represent the US population has received considerable attention in recent years. Institutional initiatives intended to increase medical student diversity have been well documented. ${ }^{1,2}$ Proposed benefits of racial diversity within US medical schools, and subsequently of physician providers, include reducing or eliminating health disparities, enhancing the ability of physicians to care for diverse patient populations, and establishing a physician workforce that encourages the involvement of diverse patients in clinical research. ${ }^{1}$ The United States Census Bureau (USCB) provides population data that includes race within four regions and nine subregions of the US. ${ }^{3-5}$ The authors were interested in comparing the racial diversity of Association of American
Correspondence: Timothy R Long Department of Anesthesiology, Mayo Clinic College of Medicine, 200 First Street SW, Rochester, MN 55905, USA

Tel + I 5072553298

Email long.timothy14@mayo.edu 
Medical Colleges (AAMC)-affiliated allopathic medical students with race demographics of the general population within the respective regions and subregions established by the USCB. We hypothesized that the race demographics of medical school matriculants (ie, enrolled medical students) would reflect the diversity of the general population in these regions. These data may help to better understand the degree of racial disparity within US allopathic medical schools.

\section{Patients and methods}

Following approval by the Mayo Clinic Institutional Review Board, the authors reviewed published data on race by region and subregion from the USCB 2010 census and the 2011 AAMC medical school enrollment and application by race and ethnicity survey. ${ }^{3,4,6,7}$ The 2011 AAMC data was selected as this was the closest available data to the USCB 2010 census. Race data were categorized by the USCB and AAMC using the following classification: White, Black/African American, American Indian/Alaskan Indian, Asian, or Native Hawaiian/ Pacific Islander. Population classification was based solely on race and not ethnicity as ethnicity data were not compatible between the AAMC and USCB databases. The USCB data contains five race classes: White (specifying ethnicity as either Hispanic/Latino or non-Hispanic), Black/African American, American Indian/Alaskan Indian, Asian, or Native Hawaiian/Pacific Islander. The AAMC database however allowed respondents to select ethnicity without selecting a race. Data from each AAMC-affiliated allopathic medical school was initially organized by state and further categorized to into the four regions and nine subregions defined by the USCB (Table 1). ${ }^{5,6}$ Expected race distribution for the general population of each geographic region and subregion was determined using the state population counts from the 2010 census for individuals 25-34 years of age, consistent with the age of the majority of medical school applicants and matriculants. ${ }^{3,4}$ Within each geographic region, the observed race distribution of enrolled medical students was compared to the expected using the chi-

Table I Regions and subregions as defined by the USCB

\begin{tabular}{ll}
\hline Northeast & New England: CT, ME, MA, NH, RI, VT \\
& Middle Atlantic: NJ, NY, PA \\
Midwest & East North Central States: IL, IN, MI, OH, WI \\
& West North Central States: IA, KS, MN, MO, NE, ND, SD \\
West & Pacific States: AK, CA, HI, OR, WA \\
& Mountain States: AZ, CO, ID, MT, NV, NM, UT, WY \\
South & East South Central States: AL, KY, MS, TN \\
& West South Central States: AR, LA, OK, TX \\
& South Atlantic States: DE, FL, GA, MD, NC, SC, VA, WV, DC \\
\hline
\end{tabular}

Abbreviation: USCB, United States Census Bureau. square test. The chi-square test was also used to compare the overall observed race distribution of medical school applicants and matriculants across all US allopathic medical schools to that expected for the overall US general population.

\section{Results}

Of the 80,279 medical students in the AAMC database, 72,122 self-identified with one of the race classifications used in this study (eg, White, Black/African American, American Indian/Alaskan Indian, Asian, or Native Hawaiian/Pacific Islander). ${ }^{6}$ Observed race distribution within US medical schools was significantly different than the expected race distribution based on USCB general population data $(P<0.001)$ overall and for each region and subregion (Figure 1 and Table 2). Asian medical students were represented higher than expected in each region and subregion of the US. All remaining races were represented lower than expected with the exception of very small population pockets for Native Hawaiian/Pacific Islander (Figure 1 and Table 2). The overall race distribution of applicants to US medical schools differs significantly to the expected race distribution of the general population $(P<0.001)$ (Figure 2$)$.

\section{Discussion}

Race demographics among the four regions and nine subregions of the US as defined by the USCB vary considerably. We aimed to explore whether or not the race demographics of medical students reflect the race demographics of the general population in the respective regions of the country. Such an analysis has not been previously reported. We found it interesting that the overall and regionally observed race distribution within US medical schools was significantly different than the expected race distribution based on USCB population data $(P<0.001)$ (Figures 1,2 and Table 2). In addition, the overall race distribution of applicants to US allopathic medical schools differs significantly to the expected race distributions of the general population $(P<0.001)$ (Figure 2).

Enhancing racial diversity within medicine may reduce health disparities, enhance care for diverse patient populations, and establish a working relationship, which encourages research that includes minority patients. ${ }^{1}$ Saha et al found that white students enrolled in more racially diverse US medical schools felt better prepared to serve minority groups and developed a better understanding of issues related to health care access. ${ }^{8}$

Institutional initiatives intended to increase the racial diversity of medical students have been well described. ${ }^{1}$ Deas 

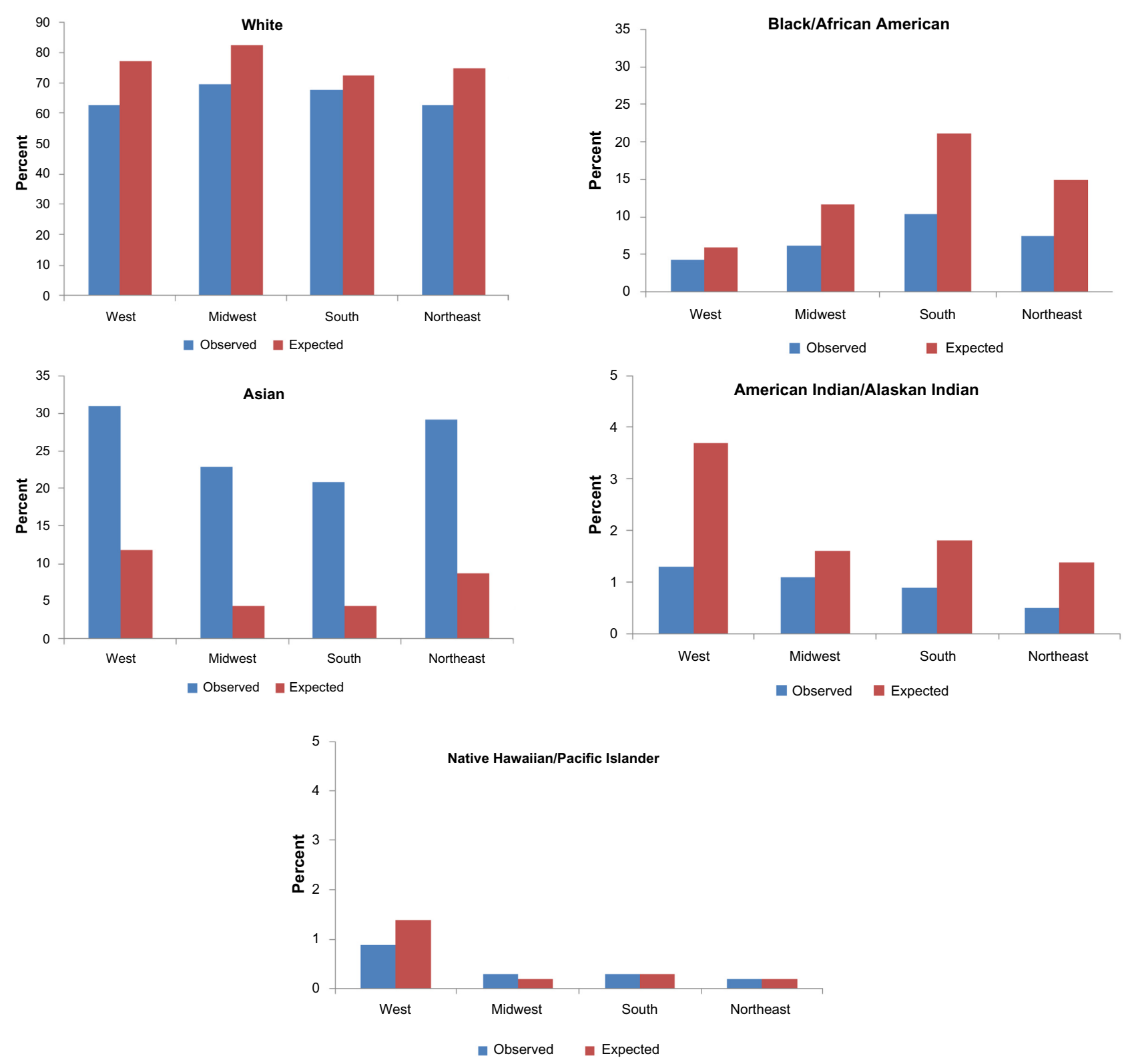

Figure I Race distribution (\%) by region for medical students (observed) and the general population (expected).

et al outline a 10-year initiative aimed to increase racial and ethnic diversity within a state-funded US medical school designed to promote a "population-representative physician workforce" that would improve health care delivery within the state. ${ }^{1}$ These efforts led to a doubling of underrepresented minorities during the 10 -year study period. The authors describe an applicant assessment formula based on four criteria (interview, medical college admission test [MCAT], grade point average [GPA], and accomplishments) with "added value" placed on criteria such as cultural experiences, rural or inner city backgrounds, serving the needs of the underserved, and others. ${ }^{1}$ Deas et al also describe a pipeline program initiated during middle school that engages more than 40 colleges and universities with the intent of increasing interest in health care careers, recruiting and fostering the development of underrepresented minorities. ${ }^{1}$

It is not possible to establish ideal enrollment goals for racial demographics within US medical schools; however, an argument made in US Supreme Court case Grutter v. Bollinger was that a "critical mass" of underrepresented minorities need be present to appreciate the beneficial influence such groups afford the surrounding population. ${ }^{9}$ Debate about whether medical school population should mirror the population of the general public on a national, regional, or subregional level is beyond the scope of this study. A survey of medical students, however, showed a majority agreed 
Table 2 Race distribution (\%) by subregion for medical students (observed) and the general population (expected)

\begin{tabular}{|c|c|c|c|}
\hline Race and subregion & $\begin{array}{l}\text { Observed } \\
(\%)\end{array}$ & $\begin{array}{l}\text { Expected } \\
(\%)\end{array}$ & $\begin{array}{l}\text { Observed/ } \\
\text { expected ratio }\end{array}$ \\
\hline \multicolumn{4}{|l|}{ White } \\
\hline East North Central & 67.2 & 80.8 & 0.83 \\
\hline East South Central & 71.0 & 74.2 & 0.96 \\
\hline Middle Atlantic & 62.3 & 72.3 & 0.86 \\
\hline Mountain & 77.2 & 85.3 & 0.91 \\
\hline New England & 63.9 & 82.3 & 0.78 \\
\hline Pacific & 57.7 & 73.8 & 0.78 \\
\hline South Atlantic & 65.9 & 69.0 & 0.95 \\
\hline West North Central & 75.4 & 85.6 & 0.88 \\
\hline West South Central & 68.8 & 77.0 & 0.89 \\
\hline \multicolumn{4}{|l|}{ Asian } \\
\hline East North Central & 25.0 & 4.5 & 5.60 \\
\hline East South Central & 12.4 & 2.1 & 5.92 \\
\hline Middle Atlantic & 29.7 & 9.3 & 3.21 \\
\hline Mountain & 17.4 & 4.5 & 3.89 \\
\hline New England & 27.7 & 7.0 & 3.97 \\
\hline Pacific & 35.6 & 14.9 & 2.38 \\
\hline South Atlantic & 21.6 & 4.9 & 4.42 \\
\hline West North Central & 18.0 & 3.9 & 4.61 \\
\hline West South Central & 24.4 & 4.5 & 5.40 \\
\hline \multicolumn{4}{|c|}{ Black/African American } \\
\hline East North Central & 6.8 & 13.4 & 0.51 \\
\hline East South Central & 15.6 & 22.4 & 0.70 \\
\hline Middle Atlantic & 7.3 & 16.7 & 0.44 \\
\hline Mountain & 2.7 & 4.7 & 0.58 \\
\hline New England & 7.7 & 9.2 & 0.83 \\
\hline Pacific & 4.7 & 6.5 & 0.73 \\
\hline South Atlantic & 11.5 & 24.4 & 0.47 \\
\hline West North Central & 4.4 & 8.0 & 0.56 \\
\hline West South Central & 5.4 & 15.4 & 0.35 \\
\hline \multicolumn{4}{|c|}{ American Indian/Alaskan Indian } \\
\hline East North Central & 0.8 & 1.2 & 0.62 \\
\hline East South Central & 0.7 & 1.1 & 0.66 \\
\hline Middle Atlantic & 0.4 & 1.4 & 0.31 \\
\hline Mountain & 2.2 & 4.8 & 0.45 \\
\hline New England & 0.5 & 1.2 & 0.44 \\
\hline Pacific & 0.9 & 3.2 & 0.30 \\
\hline South Atlantic & 0.7 & 1.4 & 0.49 \\
\hline West North Central & 1.8 & 2.3 & 0.81 \\
\hline West South Central & I.I & 2.8 & 0.41 \\
\hline \multicolumn{4}{|c|}{ Native Hawaiian/Pacific Islander } \\
\hline East North Central & 0.3 & 0.1 & 1.89 \\
\hline East South Central & 0.2 & 0.2 & 0.87 \\
\hline Middle Atlantic & 0.2 & 0.2 & 1.00 \\
\hline Mountain & 0.5 & 0.7 & 0.67 \\
\hline New England & 0.2 & 0.2 & 0.86 \\
\hline Pacific & 1.1 & 1.7 & 0.64 \\
\hline South Atlantic & 0.3 & 0.3 & 1.02 \\
\hline West North Central & 0.3 & 0.2 & 1.16 \\
\hline West South Central & 0.3 & 0.3 & 0.98 \\
\hline
\end{tabular}

that it was important that the physician workforce mirror the diversity of the society. ${ }^{10}$ Additional studies have supported the proposed benefits of diversity within medical schools, but medical student respondents specified the importance of maintaining merit in the applicant selection process. ${ }^{11}$
The disparity of racial minorities within US allopathic medical schools directly correlates with the limited overall number of applicants for such racial groups. Black/African American individuals comprise up to $21 \%$ of the population in one region, yet account for only $8 \%$ of medical school applicants. ${ }^{4,7}$ In contrast, Asian individuals represent $24 \%$ of applicants to US medical schools despite comprising less than $7 \%$ of the general population (Figure 2). ${ }^{3,7}$ Medical students of Asian race are observed at a higher rate than would be expected in every region and subregion of the US. The high level of Asian race representation is partially explained by the students' academic performance on the MCAT and overall GPA, understanding that such variables are important, but not exclusive factors in the medical school application process (Table 3). The AAMC developed an Advancing Holistic Review Initiative, which encourages viewing candidates not only on academic merit, but also on life experiences and character attributes. ${ }^{12}$ While instituting a holistic approach to the medical school admissions may slightly increase matriculation rates for underrepresented minorities, the data would suggest that racial disparity of underrepresented minorities within US medical schools is secondary to societal factors established well before application to medical school and emphasizes the importance of initiatives to enhance interest and academic qualifications among underrepresented minority students early in their formal education.

Establishing whether underrepresented minority students matriculate to medical schools within their home region or subregion or attend schools outside of such boundaries is difficult to ascertain. One might postulate that minority medical students would more closely represent the general population within geographic regions/subregions that have a higher percentage of the respective race. In other words, regions/subregions with a high population of a particular race would be more likely to have a medical school population that demonstrates a similar proportion of the respective race. However, minority medical students are actually less underrepresented (ie, medical school population closer resembles general population) within geographic regions/ subregions that have a lower percentage of the respective race in the general population. This suggests either a higher matriculation rate for students within these lower population regions/subregions or more aggressive recruitment strategies of minority students residing in regions with higher minority populations to schools within regions having lower populations (Figure 1 and Table 2). Another explanation is that certain regions/subregions with a higher general population of underrepresented minorities have lower high school 


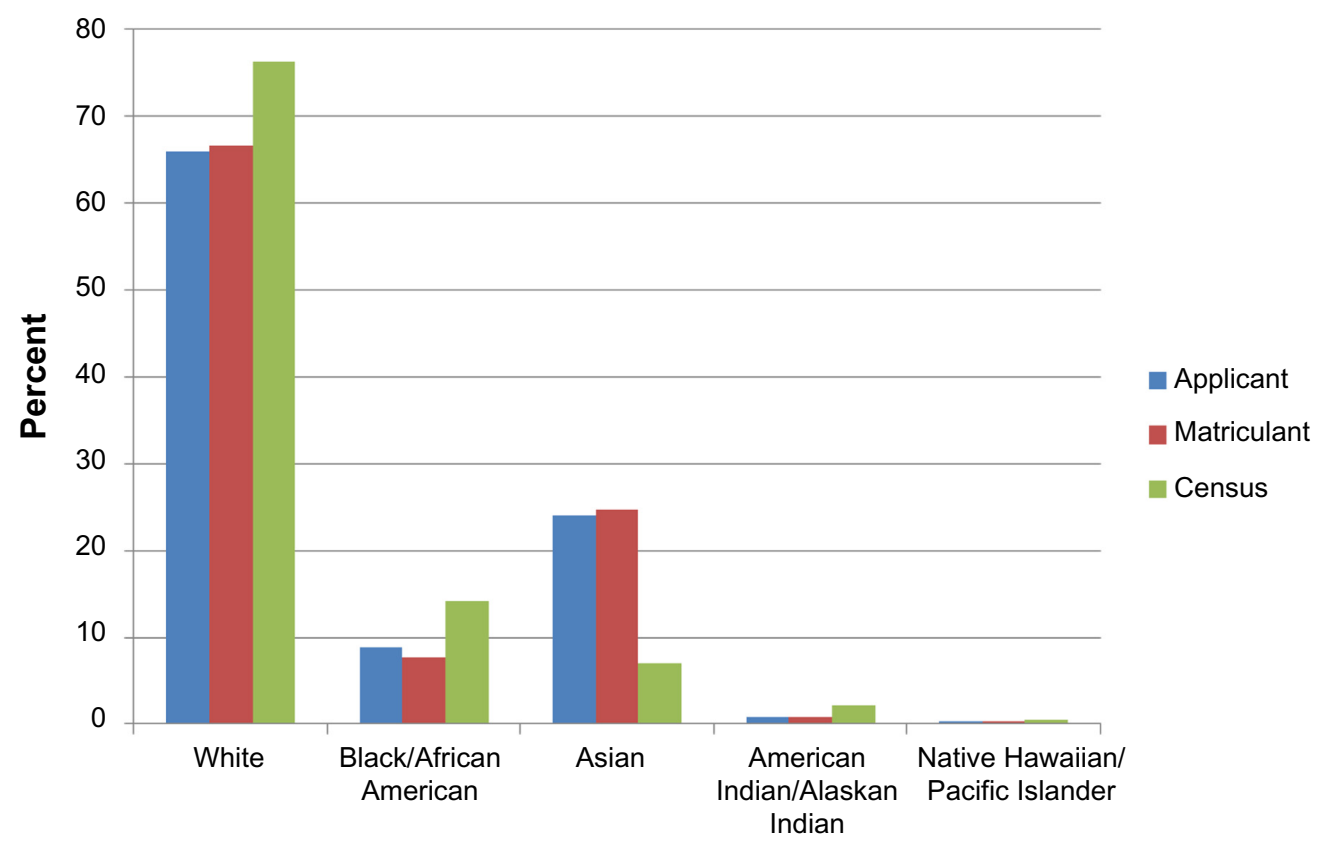

Figure 2 Percentage of population by race for US allopathic medical school applicants, matriculants, and for the general population (Census). Abbreviation: US, United States.

graduation rates, and are therefore preparing fewer students for secondary and professional education. ${ }^{13}$

The limitations of this study include that the data were analyzed on five categories of race and did not include ethnicity, as ethnicity data were not compatible between the AAMC and USCB databases. The USCB data contains five race classes: White (specifying ethnicity as either Hispanic/ Latino or non-Hispanic), Black/African American, American Indian/Alaskan Indian, Asian, or Native Hawaiian/Pacific Islander. The AAMC database, however, allowed respondents to select ethnicity without also selecting a race or not select any race or ethnicity. The frequency of such responses was low with $\leq 10 \%$ of medical students not selecting one of the five main race classifications (ie, selected only an ethnicity or did not make a race or ethnicity selection). This would

Table 3 MCAT and GPA for US allopathic medical school applicants and matriculants by race

\begin{tabular}{lllll}
\hline Race & $\begin{array}{l}\text { Applicant } \\
\text { MCAT }\end{array}$ & $\begin{array}{l}\text { Applicant } \\
\text { GPA }\end{array}$ & $\begin{array}{l}\text { Matriculant } \\
\text { MCAT }\end{array}$ & $\begin{array}{l}\text { Matriculant } \\
\text { GPA }\end{array}$ \\
\hline Asian & 29.6 & 3.56 & 32.7 & 3.72 \\
White & 29.1 & 3.59 & 31.6 & 3.72 \\
Native Hawaiian/ & 26.6 & 3.41 & 29.3 & 3.55 \\
$\begin{array}{l}\text { Pacific Islander } \\
\text { American Indian/ }\end{array}$ & 25.2 & 3.34 & 28.4 & 3.59 \\
$\begin{array}{l}\text { Alaskan Indian } \\
\text { Black/African }\end{array}$ & 22.3 & 3.26 & 27.0 & 3.45 \\
American & & & & \\
\hline
\end{tabular}

Abbreviations: MCAT, Medical College Admission Test; GPA, grade point average; US, United States. potentially lower the observed population for race categories for which medical students of the respective race selected only an ethnicity or failed to select any response. This observation is purely speculative, as the race identity of medical students selecting only an ethnicity or nonresponders cannot be determined. In addition, these data rely on accurate selfreporting with an understanding of race and ethnicity. USCB 2010 census data was analyzed for individuals 25-34 years of age as this age range was felt to be most representative of medical students, recognizing that some medical students are not within this age range.

\section{Conclusion}

In conclusion, this data demonstrates that the racial demographics of US medical school applicants and matriculants are significantly different from those of the general population. The disparity of underrepresented minorities in US allopathic medical schools may be a result of societal quandaries (eg, lack of access to academic/social support/career mentors, low high school graduation rates, low socioeconomic status, and family/community factors) present at an early stage as evidenced by considerably lower application rates of underrepresented minorities. Initiatives targeting underrepresented minorities early in formal education to enhance health care career interest and provide academic support and mentorship will be required to address the racial disparity that exists in US medical school classes and ultimately the physician workforce. 


\section{Acknowledgment}

Support was provided solely from institutional and/or departmental sources by the Mayo Clinic, Rochester, MN, USA.

\section{Disclosure}

The authors report no conflicts of interest in this work.

\section{References}

1. Deas D, Pisano ED, Mainous AG 3rd, et al. Improving diversity through strategic planning: a 10-year (2002-2012) experience at the Medical University of South Carolina. Acad Med. 2012;87(11):1548-1555.

2. Vela MB, Kim KE, Tang H, Chin MH. Improving underrepresented minority medical student recruitment with health disparities curriculum. J Gen Intern Med. 2010;25(Suppl 2):S82-S85.

3. US Census Bureau. Population Estimates. Vintage 2012: Downloadable Data Files. Available from: https://www.census.gov/popest/data/ historical/2010s/vintage_2012/datasets.html. Accessed June 24, 2014.

4. Modified Race Summary File Methodology. Available from: http://www. census.gov/popest/data/historical/files/MRSF-01-US1.pdf. Accessed June 24, 2014.

5. US Census Bureau. Census Bureau Regions and Divisions with State FIPS Codes; 2014. Available from: https://www.census.gov/popest/about/ geo/codes.html. Accessed June 30, 2014.
6. Total Enrollment by US Medical School and Race and Ethnicity, 2011. Available from: https://www.aamc.org/data/facts/enrollmentgraduate/. Accessed January 11, 2014.

7. Race and Ethnicity Responses of Applicants to US Medical Schools, 2003-2012. Available from: https://www.aamc.org/data/facts/ applicantmatriculant/. Accessed date June 30, 2014.

8. Saha S, Guiton G, Wimmers PF, Wilkerson L. Student body racial and ethnic composition and diversity-related outcomes in US medical schools. JAMA. 2008;300(10):1135-1145.

9. Grutter v. Bollinger. US2003:306. Available from: https://supreme.justia. com/cases/federal/us/539/306/case.html. Accessed April 10, 2015.

10. Wilson E, Grumbach K, Huebner J, Agrawal J, Bindman AB. Medical student, physician, and public perceptions of health care disparities. Fam Med. 2004;36(10):715-721.

11. Whitla DK, Orfield G, Silen W, Teperow C, Howard C, Reede J. Educational benefits of diversity in medical school: a survey of students. Acad Med. 2003;78(5):460-466.

12. AAMC. AAMC Advancing Holistic Review Initiative; 2015. Available from: https://www.aamc.org/initiatives/holisticreview/. Accessed March 6, 2015.

13. NCES. Public High School Graduation Rates; 2015. Available from: http://nces.ed.gov/programs/coe/indicator_coi.asp. Accessed March 6, 2015.
Advances in Medical Education and Practice

\section{Publish your work in this journal}

Advances in Medical Education and Practice is an international, peerreviewed, open access journal that aims to present and publish research on Medical Education covering medical, dental, nursing and allied health care professional education. The journal covers undergraduate education, postgraduate training and continuing medical education

\section{Dovepress}

including emerging trends and innovative models linking education, research, and health care services. The manuscript management system is completely online and includes a very quick and fair peer-review system. Visit http://www.dovepress.com/testimonials.php to read real quotes from published authors. 